\title{
Taking into Account of Functional Constraints in Optimization of Modes of Power Systems by Genetic Algorithms
}

\author{
Gayibov Tulkin Shernazarovich, Latipov Sherkhon Shuxratovich \\ Department of Power Plants, Networks and Systems, Tashkent State Technical University, Tashkent, Uzbekistan \\ Email: tulgayibov@gmail.com, 1sherkhon@mail.ru
}

How to cite this paper: Shernazarovich, G.T. and Shuxratovich, L.S. (2019) Taking into Account of Functional Constraints in Optimization of Modes of Power Systems by Genetic Algorithms. Engineering, 11, 240-246.

https://doi.org/10.4236/eng.2019.114017

Received: March 5, 2019

Accepted: April 8, 2019

Published: April 11, 2019

Copyright ( 2019 by author(s) and Scientific Research Publishing Inc. This work is licensed under the Creative Commons Attribution International License (CC BY 4.0).

http://creativecommons.org/licenses/by/4.0/

\begin{abstract}
The development of the capabilities of computational tools has created up new possibilities for the effective use of a number of classical mathematical methods and algorithms for solving many important problems in the power engineering. In particular, a set of algorithms are developed to optimize the modes of electric power systems based on genetic algorithms. At the same time, the issues of taking into account functional constraints in solving such problems by genetic algorithms need to be improved. In accordance with it in this article the problems of taking into account of different constraints in optimization of modes of power systems using genetic algorithms are considered. The algorithm of optimization by genetic algorithm taking into account of functional constraints in forms of equality and inequality by penalty functions is proposed. The results of research of proposed algorithm's efficiency in example of optimization of mode of power system with 8 buses, 4 thermal power plants and 3 transmission lines with controlled power flow are presented.
\end{abstract}

\section{Keywords}

Optimization, Power System, Power Plant, Objective Function, Constraint

\section{Introduction}

Optimization of modes of modern power systems on active power is a complex task of nonlinear mathematical programming with a set of simple and functional constraints in the forms of equality and inequality. Therefore, the effectiveness of algorithms of its solution is determined, in particular, by the possibility of effectively taking into account such constraints.

The main constraints that are taken into account in solving the problem of 
optimal planning of modes of power systems with thermal power plants for a certain period of time are:

- constraints in the form of inequality on minimum and maximum possible loads of power plants (simple constraints)

$$
P_{i}^{\min } \leq P_{i} \leq P_{i}^{\max }, i=1,2, \cdots, n ;
$$

- condition of active power balance in power system (functional constraint in the form of equality)

$$
\sum_{i=1}^{n} P_{i}=P_{L},
$$

where $n$ is the number of power plants, which participate in optimization; $P_{i}$ - power of $i$ th plant; $P_{L}$-the total load of consumers in power system;

- constraints on power flows along certain controlled transmission lines (functional constraints in the form of inequality)

$$
P_{l}^{\min } \leq P_{l} \leq P_{l}^{\max }, l=1,2, \cdots, L,
$$

where $L$ is the number of lines in which active power flows are limited; $P_{\Gamma}$ active power flow along the th controlled line.

At present, the methods for taking into account such constraints in optimization of modes of power systems by traditional algorithms are quite developed [1] [2] [3] [4]. However, the issues of taking into account functional constraints in solving of optimization problems using nontraditional algorithms, in particular, genetic algorithms [5] [6] [7] [8], require additional research.

Genetic algorithms offer a new and powerful approach to solving optimization problems. Their use was made possible by expanding the capabilities of computational tools at relatively low costs. Recently, these algorithms are used in solving global problems of search optimization, when traditional optimization algorithms cannot be used. They use parallel and global search methods that mimic natural genetic operators. The probability of convergence of a genetic algorithm to the global solution of the problem is the highest, since it simultaneously evaluates a set of points in the parameter space. These algorithms also do not require differentiability and continuity of the search space. At the same time, the issues of taking into account of functional constraints in the form of equality and inequality in optimization of power system modes by these algorithms are researched not sufficiently.

\section{The Algorithms of Taking into Account of Functional Constraints}

The issues of using the genetic algorithms for optimal distribution of consumers load in power system between thermal power plants were researched by author of this paper in [9] In present paper, on the basis of researches carried out the algorithm of taking into account of functional constraints in the form of equality and inequality in optimization of modes of power system by genetic algorithms is proposed. According to this algorithm, the problem of conditional minimiza- 
tion of a function, which is a function of total fuel costs or total consumption of reference fuel $B$ in thermal power plants of the power system, is reduced to unconditional minimization of a generalized function consisting of sum of the objective function of the initial problem and the penalty functions that take into account constraints (2) and (3). Simple constraints (1) are taken into account in accordance with the procedure of the genetic algorithm automatically.

The value of penalty function that take into account of the constraint should be equal to zero when it is satisfied and increase proportionally to the degree of violation when the constraint is not satisfied.

In accordance with it, in order to take into account the constraint in the form of equality (2), the penalty function is taken in the form of

$$
S_{P}=\alpha\left(\sum_{i=1}^{n} P_{i}-P_{L}\right)^{2} \text {. }
$$

Particular difficult is the problem of taking into account of functional constraints in the form of inequality (3). In many traditional algorithms of power systems mode optimization such constraints are also taken into account by quadratic penalty functions as

$$
S_{l}=\alpha\left(P_{l}-P_{l}^{\max }\right)^{2} \text { or } S_{l}=\alpha\left(-P_{l}+P_{l}^{\min }\right)^{2} .
$$

This form of the penalty function is adapted for taking into account of constraints in the form of equality. For example, to take into account of constraint $P_{l} \leq P_{l}^{\max }$ in the task of finding the minimum of an objective function, the penalty function has a positive value and grows even when the constraint is satisfied (Figure 1(a)).

To overcome this difficulty in traditional algorithms of optimization after each iteration of the optimization process, the constraint is checked out. In the case of its satisfying the next step of calculation is carried out without taking into account of this constraint. Otherwise, it is carried out with taking into account of the constraint using the penalty function.

The results of research show that taking into account of functional constraints in the form of inequality using such penalty functions in optimization by traditional

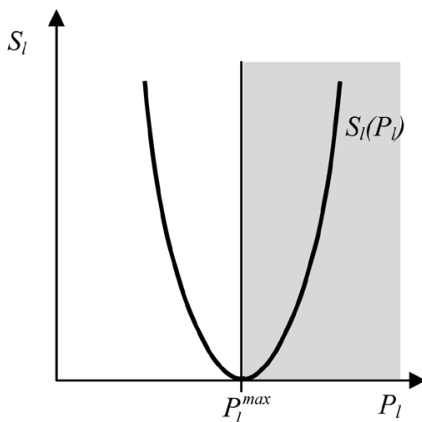

(a)

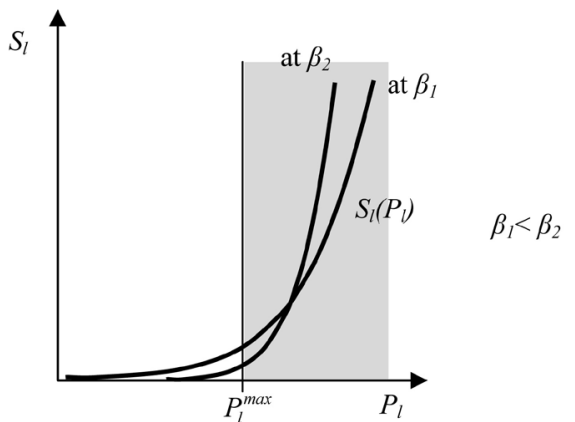

(b)

Figure 1. The curves of penalty functions: (a) The curve of quadratic penalty function; (b) The curve of exponential penalty function. 
algorithms generally cause some difficulties connected with choosing the penalty coefficients and ensuring the convergence of the iterative calculating process, which is often oscillatory in nature [1].

There are some difficulties for taking into account the constraints in the form of inequality (3) using penalty functions (5) in optimization by genetic algorithms. Since the use of the objective function and the corresponding fitness function, which do not include such constraints may lead to unacceptable results, where some of these constraints are not satisfied. Therefore, for overcome of such difficulties in this work the use of the exponential form of penalty function is recommended:

$$
S_{l}=\alpha e^{\beta\left(P_{l}-P_{l}^{\max }\right)} \text { or } S_{l}=\alpha e^{\beta\left(-P_{l}+P_{l}^{\min }\right)},
$$

where $\alpha, \beta$ are weight (penalty) coefficients.

This form of penalty function is very closely meets the requirements set for it-equality to zero when the constraint is satisfied and increase proportionally to degree of violation when it is not satisfied (Figure 1(b)).

By selecting the values of the penalty coefficients $\alpha$ and $\beta$, it is possible to take into account the constraints with sufficient accuracy.

Thus, the generalized objective function when optimized by the genetic algorithm taking into account of constraints is presented in the following form:

$$
F=B+S_{P}+\sum_{l} S_{l} .
$$

\section{Example and Evaluation of Results}

The efficiency of the described algorithm is researched in example of optimization of mode of power system with 8 buses and 13 power transmission lines (PTL) (Figure 2). In 4 buses there are thermal power plants (TPP) with the following fuel consumption characteristics of equivalent fuel, toe $/ \mathrm{h}$ :

$$
\begin{gathered}
B_{0}=70+0.14 P_{0}+0.0014 P_{0}^{2}, \quad B_{1}=84+0.14 P_{1}+0.00175 P_{1}^{2}, \\
B_{6}=42+0.105 P_{6}+0.00105 P_{6}^{2}, \quad B_{7}=56+0.175 P_{7}+0.0007 P_{7}^{2} .
\end{gathered}
$$

The constraints on the minimum and maximum loads of TPPs are the same and $P^{\text {min }}=200 \mathrm{MW}, P^{\max }=700 \mathrm{MW}$. Capacities of consumers are: $P_{2}=400 \mathrm{MW}$, $P_{3}=600 \mathrm{MW}, P_{4}=200 \mathrm{MW}, P_{5}=500 \mathrm{MW}$.

Three power transmission lines have limited active power flows:

$$
P_{6-3} \leq 450 \mathrm{MW}, P_{6-5} \leq 65 \mathrm{MW}, P_{0-3} \leq 95 \mathrm{MW} \text {. }
$$

Power flows for these controlled transmission lines are determined using distribution coefficients $C_{l p}$ given in Table 1, on following expression:

$$
P_{l}=\sum_{i=1}^{n} C_{l i} P_{i}+P_{l 0} .
$$

To compare the results of optimization on the proposed algorithm, Table 2 shows the reference result obtained by the classical gradient method.

The results of optimization by the genetic algorithm, taking into account of 
Table 1. Distribution coefficients of buses power over controlled transmission lines.

\begin{tabular}{cccccccc}
\hline \multirow{2}{*}{ Power lines suses } \\
\cline { 2 - 8 } & 1 & 2 & 3 & 4 & 5 & 6 & 7 \\
\hline $6-3$ & 0.2536 & -0.0713 & -0.1720 & 0.4106 & 0.4890 & 0.6343 & 0.4986 \\
$6-5$ & -0.0701 & 0.02025 & 0.0484 & -0.2810 & -0.4223 & 0.1029 & -0.2986 \\
$0-3$ & -0.1400 & -0.1735 & -0.2670 & -0.1744 & -0.1917 & -0.2240 & -0.1939 \\
\hline
\end{tabular}

Table 2. Reference result of optimization.

\begin{tabular}{ccc}
\hline TPP & Power of TPP, MW & Fuel consumption, toe $/ \mathrm{h}$. \\
\hline TPP at bus 0 & 234.7 & 179.97 \\
TPP at bus 1 & 505.6 & 602.14 \\
TPP at bus 6 & 281.3 & 154.55 \\
TPP at bus 7 & 678.4 & 496.88 \\
Total fuel consumption in power system & - & 1433.54 \\
Power flow on controlled lines & $P_{6-3}=450.0 \mathrm{MW}, P_{6-5}=21.2 \mathrm{MW}, P_{0-3}=95.0 \mathrm{MW}$. \\
\hline
\end{tabular}

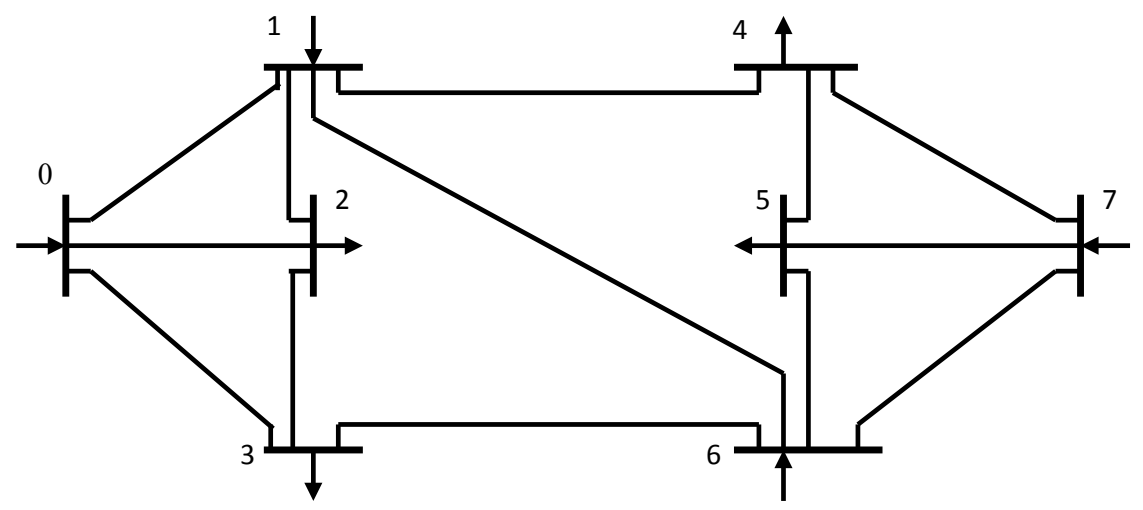

Figure 2. Power system circuit.

constraints using proposed algorithm at values of weighting coefficients $\alpha=10$, $\beta=2$ are given in Table 3 .

Comparing the obtained results of optimization by proposed algorithm with the reference result, we will verify the sufficiently high accuracy of the proposed algorithm.

Thus, the proposed algorithm of taking into account of functional constraints in the form of equality and inequality in optimization of power systems mode by genetic algorithms is highly efficient. It allows you to reliably determine the optimal mode of power system taking into account simple and functional constraints in the form of equality and inequality with acceptable accuracy for practical purposes.

\section{Conclusions}

1) The efficient algorithm for taking into account of functional constraints in 
Table 3. Optimization results with taking into account of constraints by proposed algorithm.

\begin{tabular}{rcc}
\hline TPP & Power of TPP, MW & Fuel consumption, toe $/ \mathrm{h}$. \\
\hline TPP at bus 0 & 236.9 & 181.74 \\
TPP at bus 1 & 498.8 & 589.23 \\
TPP at bus 6 & 273.7 & 149.39 \\
TPP at bus 7 & 690.5 & 510.59 \\
Total fuel consumption in power system & - & 1430.96 \\
Power flow on controlled lines & $P_{6-3}=449.5 \mathrm{MW}, P_{6-5}=17.2 \mathrm{MW}, P_{0-3}=95.3 \mathrm{MW}$. \\
\hline
\end{tabular}

the form of equality and inequality in optimization of modes of power systems by genetic algorithm is proposed.

2) Genetic algorithm for optimization of modes of power systems taking into account the functional constraints in the form of inequalities by exponential form of penalty function has a reliable convergence of an iterative calculation process. It also does not require differentiability and continuity of the search space.

3) The proposed algorithm of taking into account of functional constraints in optimization by genetic algorithms can be effectively used for optimal planning of short-term modes of power systems.

\section{Conflicts of Interest}

The authors declare no conflicts of interest regarding the publication of this paper.

\section{References}

[1] Nasirov, T.Kh. and Gayibov, T.Sh. (2014) Teoreticheskie osnovi optimizatsii rejimov energosystem [Theoretical Foundations of Optimization of Modes of Power Systems]. Fan va Texnologiya Publishing, Tashkent. (In Russian)

[2] Rudenko, Yu.N. and Semyonov, V.A. (2000) Avtomatizatsiya dispetcherskogo upravleniya v elektroenergetike [Automation of Dispatching Control in Electric Power Industry]. MEI Publishing, Moscow. (In Russian)

[3] Murty, P.S.R. (2008) Operation and Control in Power Systems. B.S. Publications, Hyderabad.

[4] Tulkin, G. and Kamal, R. (2017) Optimal Planning of Short-Term Modes of Power Systems with Control of Loads of Electric Consumers Taking into Account of Network Factor. European Science Review, 9-10, 86-91.

[5] Yuryevich, J. and Wong, K.P. (1999) Evolutionary Programming Based Optimal Power Flow Algorithm. IEEE Transaction on Power Systems, 14, 1245-1250. https://doi.org/10.1109/59.801880

[6] Lai, L.L., Ma, J.T., Yokoma, R. and Zhao, M. (1997) Improved Genetic Algorithms for Optimal Power Flow under Both Normal and Contingent Operation States. Electrical Power \& Energy System, 19, 287-292. https://doi.org/10.1016/S0142-0615(96)00051-8 
[7] Amin, N., Marowan, A.Q. and Ghosh, B.C. (2017) Application of Genetic Algorithm in Power System Optimization with Multi-Type FACTS. International Journal of Research Publications, 7, 748-754.

[8] Bhaskar, K., Vijay, M., William, A. and Bhattacharya, D. (2013) Mathematical Modeling of Optimizing Power Stream Measurement Using Genetic Algorithm. American Journal of Engineering Research (AJER), 2, 71-79.

[9] Gayibov, T.Sh. (2017) Optimizatsiya rejimov energosistem geneticheskimi algiritmami [Optimization of Power Systems Modes by Genetic Algorithms]. Problems of Energy and Resource Saving, 1-2, 43-48. 